Original Research Paper

\title{
Kinematics of the Basic Mechatronic Module 3R of an Anthropomorphic Robot
}

\author{
Florian Ion Tiberiu Petrescu \\ ARoTMM-IFToMM, Bucharest Polytechnic University, Bucharest, (CE) Romania
}

Article history

Received: 30-12-2020

Revised: 06-02-2021

Accepted: 08-02-2021

Email: fitpetrescu@gmail.com

\begin{abstract}
The kinematics of the basic mechatronic module $3 \mathrm{R}$ of an anthropomorphic robot will be presented in this study, through an original geometric-analytical method, developed by the author. The advantages of the proposed new method are a great simplicity of calculations and calculation relations, intertwined with very high precision. The method is a strong one from a physical-mathematical point of view. There is a counter that must be set correctly to plus or minus 1 , otherwise, all values and calculations are fast, accurate, direct, intuitive. The method has already been verified by the author with another original, older, trigonometric one and the results obtained by both methods are identical. If the trigonometric method already presented previously was a simple one, the geometric-analytical one proposed this time is even simpler in calculations and more precise, the effective work being to present the method and the calculation relations as well as the way they were deducted, but their use is very simple and fast.
\end{abstract}

Keywords: Kinematics, Mechatronic Module 3R, Anthropomorphic Robot, A Geometric-Analytical Method

\section{Introduction}

Robots have always fascinated us, but today we use them massively, in almost all industrial areas, especially where they work hard, repetitive and tiring, in toxic, chemical, radioactive environments, underwater, in the cosmos, in dangerous environments, on mined lands, in hard to reach areas, etc. It can be said once again that just as software and microchips have helped us to write various useful programs quickly and to implement them directly, so robotics has made our daily work much easier. Thanks to robots, automation is almost perfect today, the quality of the products is very high, the manufacturing price has dropped a lot, you can work in continuous fire, people have escaped hard work, tiring, repetitive, in toxic environments and can now deal other more important issues, such as design, scientific research, working only 5 days a week with high incomes and in the future also due to the massive implementation of increasingly modern robots with increased capabilities, man will reach the week of work only 4 days.

An even greater increase is expected in the number of specialized robots implemented in large factories and factories around the world (Fig. 1).

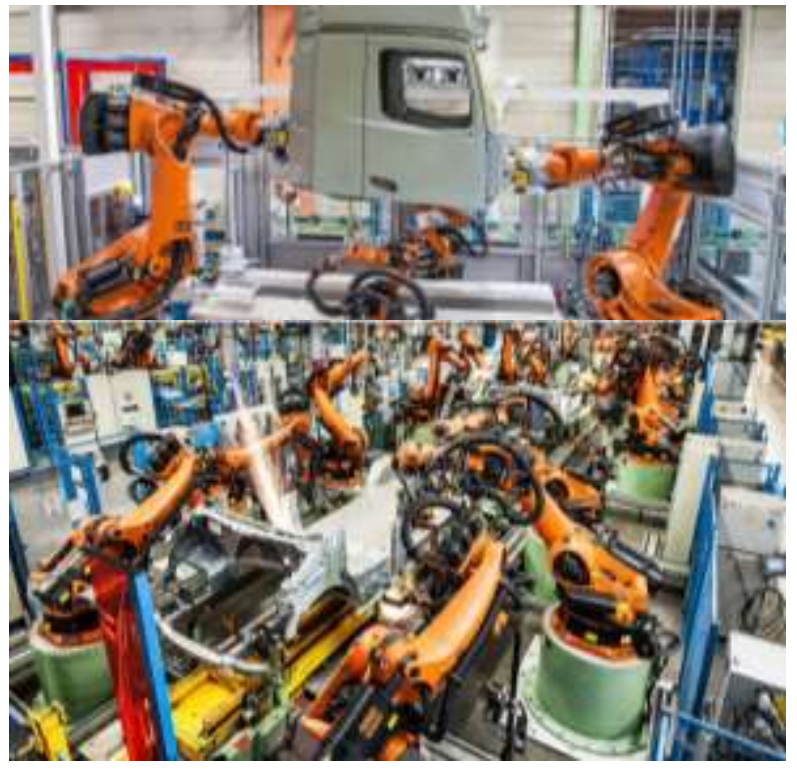

Fig. 1: Robotic line in the Mercedes factory

The initial problem was greatly diminished when the unions demanded the elimination of robots as enemies who kidnap people's jobs, but even today 
unions sometimes negotiate the introduction of workers with robots in fully automated production lines and it is very dangerous to work side by side elbow people with robots, it was established at Mercedes for example that the workers are the ones who will practically assemble the Mercedes logo in the end, obviously after the whole car was created and assembled automatically only with robots.
Whether processing, translating, rotating, processing, painting, cutting, welding, assembling robots, the vast majority of robotic models used today in the factory even in complex robotic cells, use anthropomorphic robots with several degrees of freedom, able to develop high powers and torques, fast and dynamic, simple and cheap, economical, with sufficient stability and a suitable workspace for the necessary operations (Fig. 2-5).

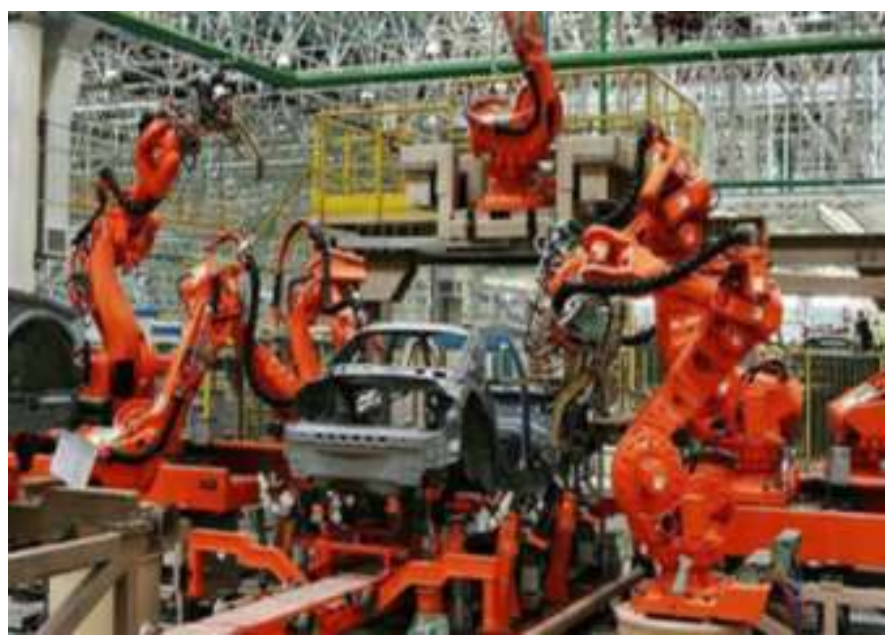

Fig. 2: Total industrial automation with simple anthropomorphic robots

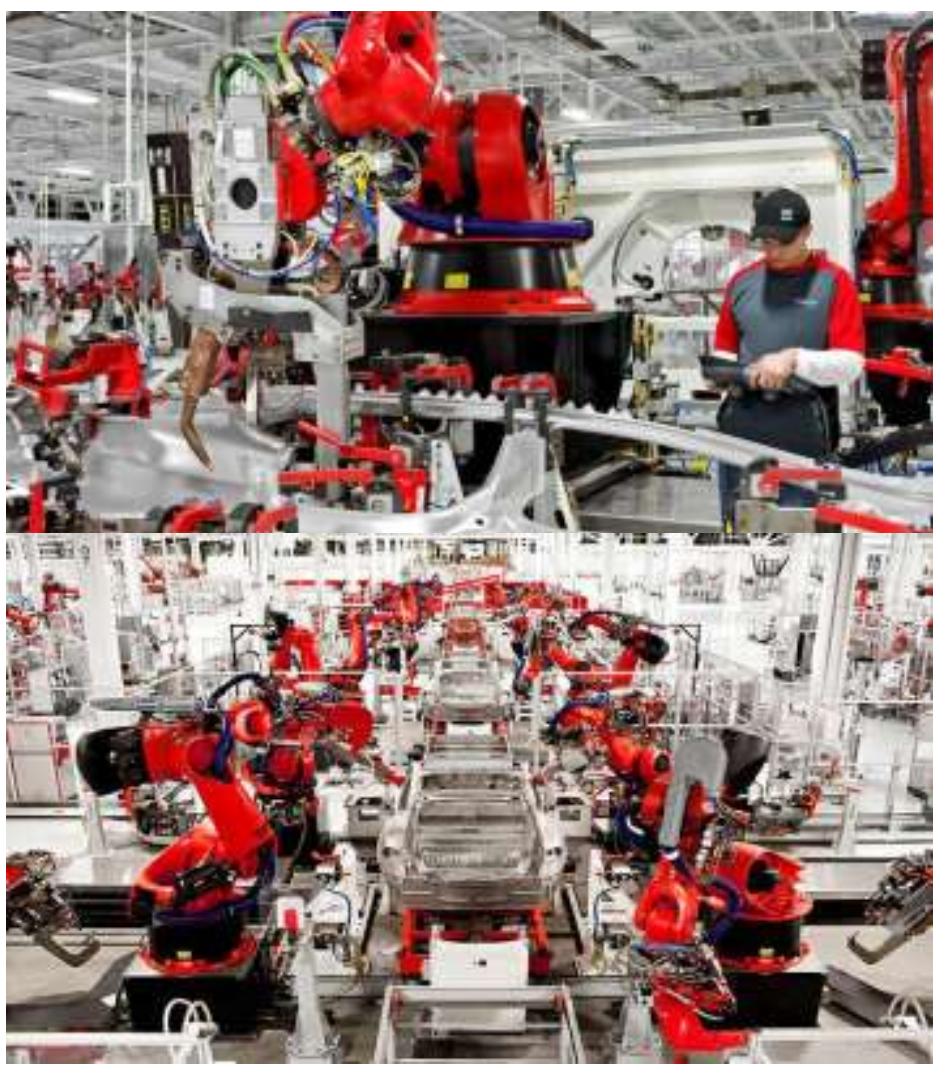

Fig. 3: Automation with Tesla anthropomorphic robots 


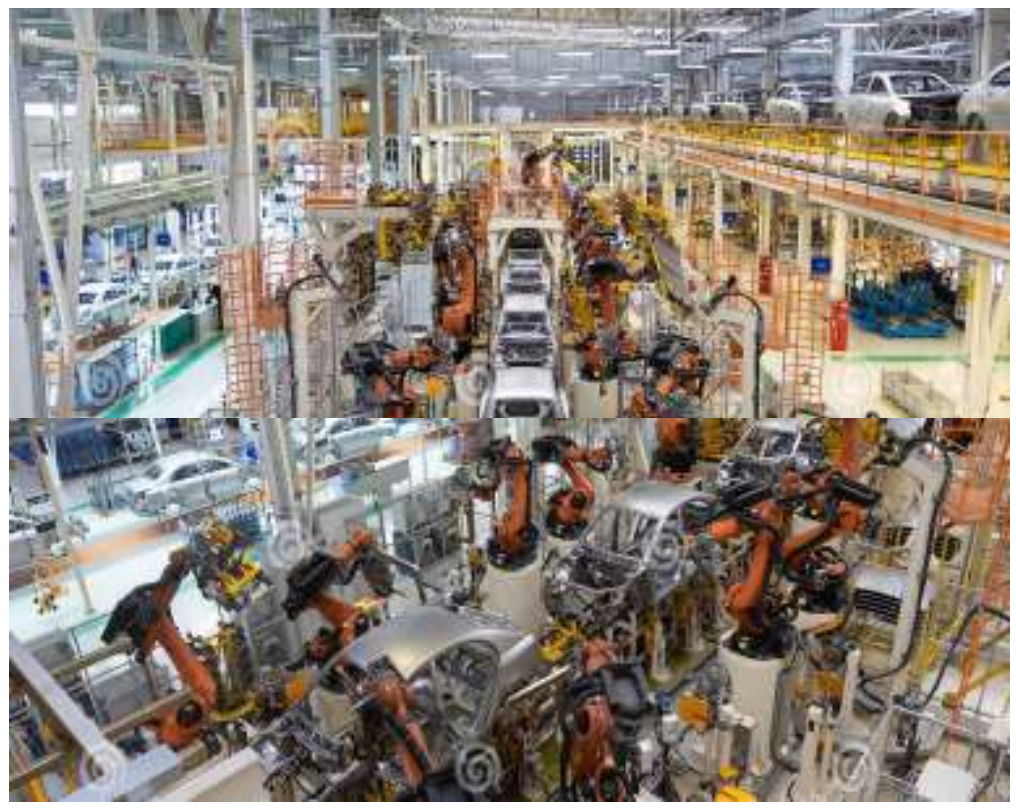

Fig. 4: An assembly line production of some new cars. Automated welding of the car body on the production line; the robotic arm on the car production line is working

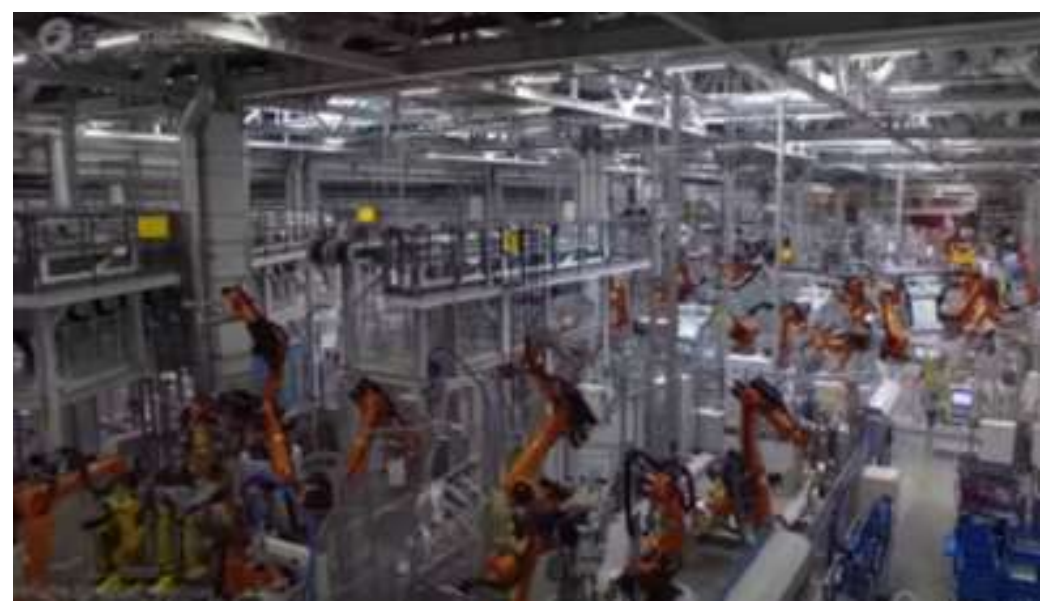

Fig. 5: BMW 5 Series CAR FACTORY

As we have shown in other previous works, anthropomorphic robots all have a basic spatial structure (Fig. 6), which can be studied more simply in plan (Fig. 7) if we eliminate the rotational module that rotates the flat platform in various directions (thus transforming the flat base motion into a spatial motion).

About $90 \%$ of anthropomorphic robots are used worldwide today because they can be designed, built and implemented easier, cheaper and are very reliable (Anderson, 1997; CEUP, 2018; García, 2020; Rana, 2020; Garfo et al., 2020; Kumar and Sreenivasulu, 2019; Mishra and Sarawagi, 2020; Welabo and Tesfamariamr, 2020; Antonescu and Petrescu, 1985; 1989; Antonescu et al., 1985a; 1985b; 1986; 1987; 1988;
1994; 1997; 2000a; 2000b; 2001; Aversa et al., 2017a; 2017b; 2017c; 2017d; 2016a; 2016b; 2016c; 2016d; Ayiei, 2020; Brewer, 1991; Chilukuri et al., 2019; Cao et al., 2013; Dong et al., 2013; Saheed et al., 2019; Riman, 2019; Matthews and Yi, 2019; Dwivedi et al., 2019a; 2019b; Eremia, 2020; Franklin, 1930; Hanrahan, 2014; He et al., 2013; Hertel, 2017; Komakula, 2019; Langston, 2015; 2016; Lee, 2013; Lin et al., 2013; Liu et al., 2013; Padula and Perdereau, 2013; Perumaal and Jawahar, 2013; Petrescu, 2011; 2012; 2019a-v; 2020a-g; Petrescu and Petrescu, 2019a-f; 1995a; 1995b; 1997a-c; 2000a-b; 2002a-b; 2003; 2005a-e; 2011a-c; 2012a-b; 2013a-e; 2014a-h; 2016ac; 2020; Petrescu et al., 2007; 2009; 2016; 2017a-ak; 
2018a-w; 2020; Petrescu and Calautit, 2016a-b; Dekkata and Yi, 2019; Fahim et al., 2019; El Hassouni et al., 2019; Riman, 2018; Nacy and Nayif, 2018; Kortam et al., 2018; Welch and Mondal, 2019; Eissa et al., 2019; Younes et al., 2019; Svensson et al., 2004; Rahman, 2018; Richmond, 2013; Kisabo et al., 2019a; 2019b; Kisabo and
Adebimpe, 2019; Kosambe, 2019a; 2019b; 2019c; 2019d; Sharma and Kosambe, 2020; Oni and Jha, 2019; Chaudhary and Kumar, 2019; de Lima et al., 2019; Babu et al., 2019; 2020; de Mota Siqueira et al., 2020; Tumino, 2020; Mishra, 2020a; 2020b; Brischetto and Torre, 2020; Vladescu, 2020).

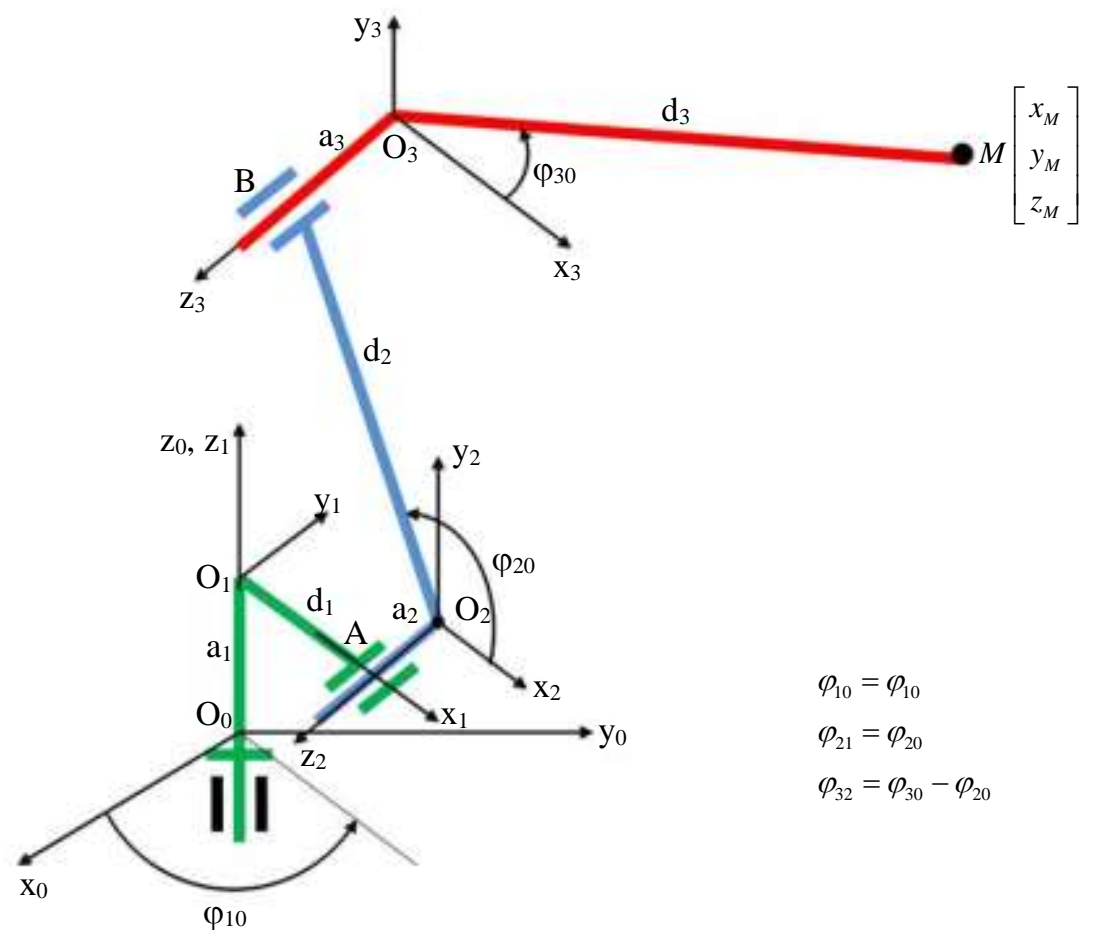

Fig. 6: The basic spatial structure

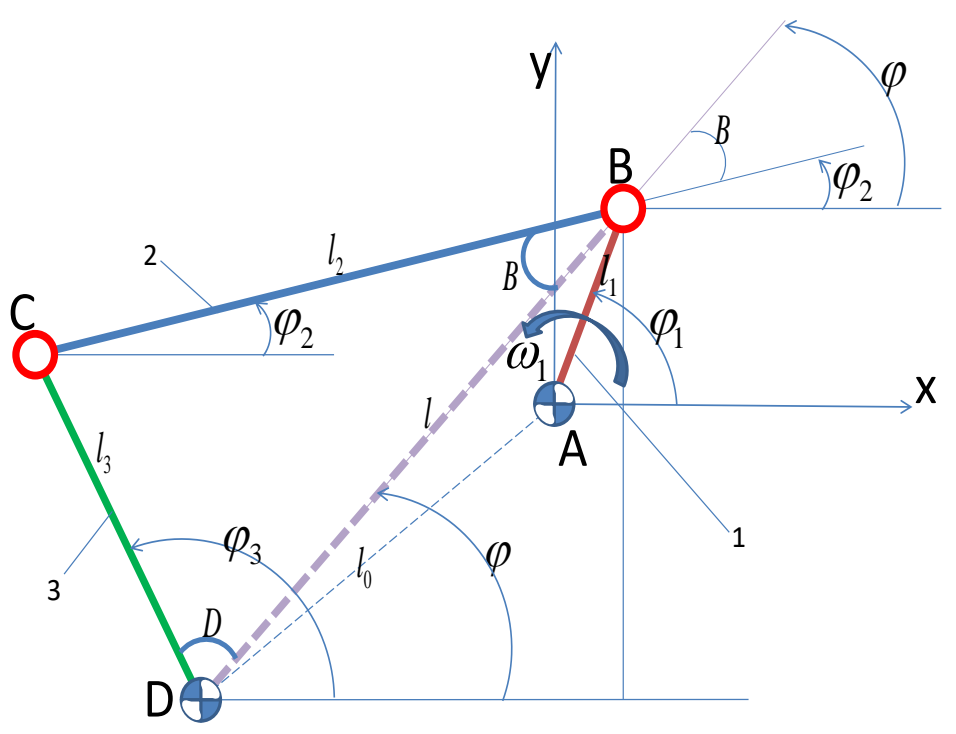

Fig. 7: The basic planar structure driven in reverse kinematics by a crank so that the exit point performs a complete rotation 


\section{Materials and Methods}

The structure of Fig. 8 consists of two elements connected to each other by a fifth-class flat rotational coupling at point $\mathrm{C}$ and having at the ends one or even two other fifth-class rotational couplings.

Usually the outer coupling, from point $B$, of entry, is also a flat rotation torque as the inner one from $C$ and in $D$ it can only be a working point of the respective manipulator or robot, or another external coupling can be caught, to which the defector is connected, i.e., the final device of the robot: It can be a gripper, i.e., a gripping, gripping and handling device, it can be a welding electrode, it can be a paint gun, a soldering iron, a any working device, or an arm may be placed to extend the working capabilities of the robot; In point $D$, therefore, there may be no more couplings, there may be a fifth-class plane of rotation as well as those in points $B$ and $C$, or there may be another coupling, for example spatial; if the module consisting of the two arms 2 and 3 is used and/or only at, any mechanism, the simplest being the planar quadrilateral mechanism, or the articulated quadrilateral mechanism, which has the kinematic scheme shown in the figure at the top left, then the module is mandatory from the studied right will have a kinematic torque of rotation, plane, of the fifth class and in point $D$, the module 2-3 having in this case the name of structural group, of type: Dyad 3R. This case being the most general (complete) we will start in this study with it and we will study the direct and indirect kinematics of this module (dyad 3R) that we saw that it can be used, generalize to the vast majority of anthropomorphic robots. The classic robots are of the anthropomorphic type, i.e., serial robots and most of them have rotational movements, the drives being made with stepping actuators (motors). All anthropomorphic structures are based on a $3 \mathrm{R}$ robot as can be seen in Fig. 6.

The idea is to greatly simplify the calculations and relationships (including the classical methods used), moving from spatial study to different planes. It can be seen that if we separate the rotational movement $\varphi_{10}$ from the basic plane $x_{0} O_{0} y_{0}$, decoupling it from the other rotational movements $\varphi_{20}$ and $\varphi_{30}$ we arrive at our module, where the torque in $\mathrm{B}$ is denoted here by $A\left(\mathrm{O}_{2}\right.$, being a point constructive), the coupling in $C$ is denoted here with $\mathrm{B}$ ( $\mathrm{O}_{3}$ being a constructive point) and the coupling or working point of the end-effector in $D$ is denoted here with $M$. This idea greatly simplifies the classical spatial calculations, especially those for reverse kinematics, because this is the most difficult, presented in the course of SMMSP) transforming them into plane calculations (follow the complete method in the course "Mechatronics-SSP").

The proposed study module will be in this topic (the complete, general plan of a structural group, type: Dyad $3 R$, or dyad RRR; see the kinematic diagram of the module in the figures). We always know (give) the constant lengths of the two elements of the module: $l_{2}$ and $l_{3}$, the positions of the outer coupling, input $B\left(\mathrm{xB}, y_{B}, z_{B}\right)$, in our case, with flat treatment $B\left(x_{B}, y_{B}\right)$. In direct kinematics, the simpler position angles $\varphi_{2}$ and $\varphi_{3}$ are also known and the positions of the point (outer coupling) $D$, i.e., $\left(x_{D}, y_{D}\right)$, are required. In inverse kinematics (our topic), the positions of the defector $D$, i.e., $x_{D}, y_{D}$, are also known, imposed (imposed) and the position angles $\varphi_{2}$ and $\varphi_{3}$ are required (to be determined) Fig. 9.

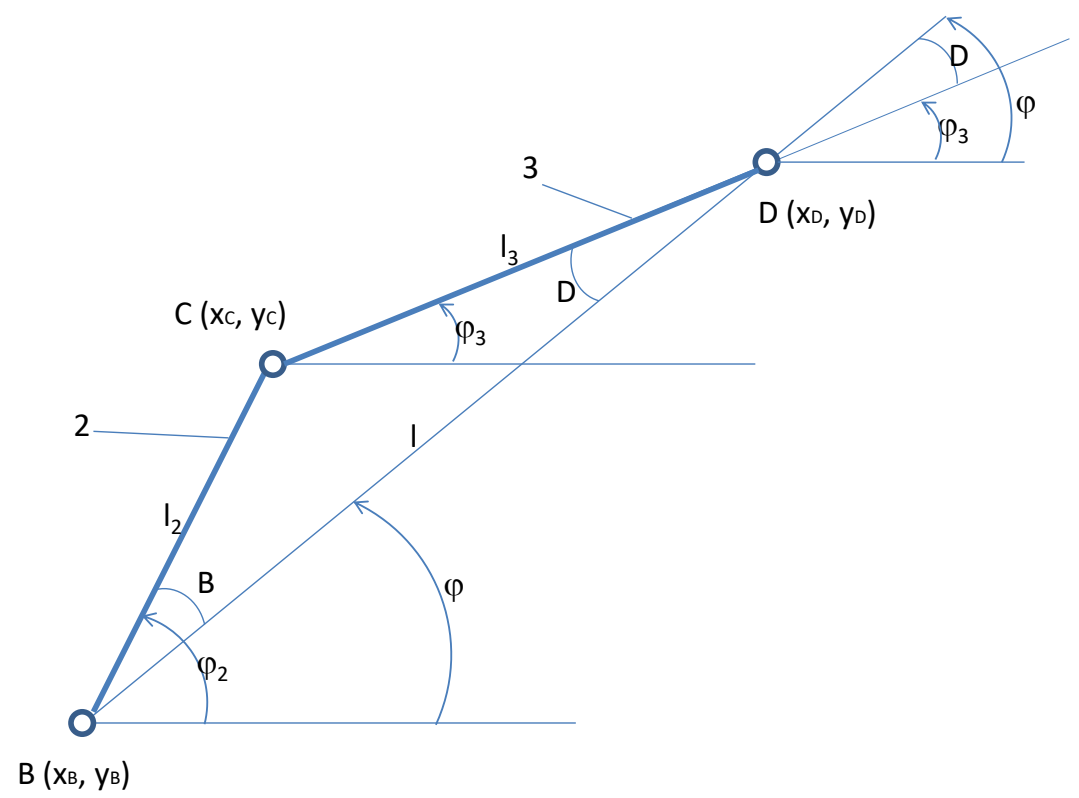

Fig. 8: The basic planar anthropomorphic structure 


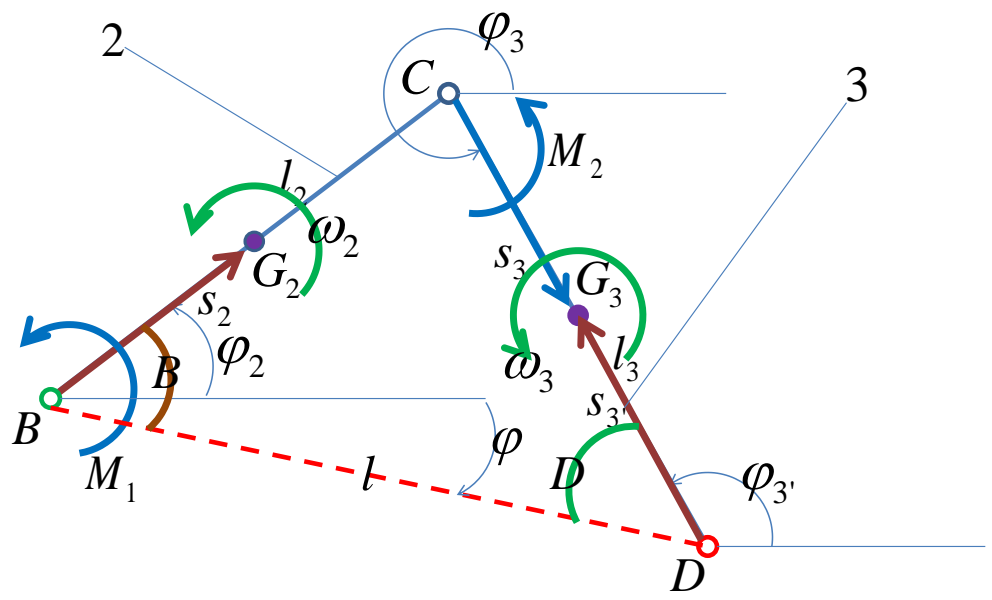

Fig. 9: Reverse kinematics at the basic mechatronic module plan $3 R$

If at the old presented method, the trigonometric one, the angles FI2 and FI3 were determined first of all and then with their help the scalar parameters of point $C$ can be calculated (Fig. 9, Eq. 1), by the newly proposed method, geometric-analytical is determined directly the scalar coordinates of the point (couples) $C$ (Eqs. 2 and 3) and then to calculate the two angles FI2 and FI3 easily now that all the scalar coordinates of all the couples of the mechatronic module $(B, C$ and $D)$ are known:

$$
\left\{\begin{array}{l}
x_{C}=x_{B}+l_{2} \cdot \cos \varphi_{2} \\
y_{C}=y_{B}+l_{2} \cdot \sin \varphi_{2} \\
o r \\
x_{C}=x_{D}-l_{3} \cdot \cos \varphi_{3} \\
y_{C}=y_{D}-l_{3} \cdot \sin \varphi_{3}
\end{array}\right.
$$

$$
\left\{\begin{array}{l}
x_{C}=x_{B}+l_{2} \cdot \cos \varphi_{2} \Rightarrow \cos \varphi_{2}=\frac{x_{C}-x_{B}}{l_{2}} \\
y_{C}=y_{B}+l_{2} \cdot \sin \varphi_{2} \Rightarrow \sin \varphi_{2}=\frac{y_{C}-y_{B}}{l_{2}} \\
\Rightarrow \varphi_{2}=\arccos \left(\cos \varphi_{2}\right) \cdot \operatorname{sign}\left(\sin \varphi_{2}\right) \Rightarrow \\
\Rightarrow \varphi_{2}=\arccos \left(\frac{x_{C}-x_{B}}{l_{2}}\right) \cdot \operatorname{sign}\left(\frac{y_{C}-y_{B}}{l_{2}}\right) \\
x_{D}=x_{C}+l_{3} \cdot \cos \varphi_{3} \Rightarrow \cos \varphi_{3}=\frac{x_{D}-x_{C}}{l_{3}} \\
y_{D}=y_{C}+l_{3} \cdot \sin \varphi_{3} \Rightarrow \sin \varphi_{3}=\frac{y_{D}-y_{C}}{l_{3}} \\
\Rightarrow \varphi_{3}=\arccos \left(\cos \varphi_{3}\right) \cdot \operatorname{sign}\left(\sin \varphi_{3}\right) \Rightarrow \\
\Rightarrow \varphi_{3}=\arccos \left(\frac{x_{D}-x_{C}}{l_{3}}\right) \cdot \operatorname{sign}\left(\frac{y_{D}-y_{C}}{l_{3}}\right)
\end{array}\right.
$$

$$
\left\{\begin{array}{l}
\varphi_{2}=\arccos \left(\frac{x_{C}-x_{B}}{l_{2}}\right) \cdot \operatorname{sign}\left(\frac{y_{C}-y_{B}}{l_{2}}\right) \\
\varphi_{3}=\arccos \left(\frac{x_{D}-x_{C}}{l_{3}}\right) \cdot \operatorname{sign}\left(\frac{y_{D}-y_{C}}{l_{3}}\right)
\end{array}\right.
$$

In other words, it is much simpler and more precise to first determine the scalar coordinates of the coupling $C\left(x_{C}\right.$ and $\left.y_{C}\right)$ and then the angles FI2 and FI3 (with Eq. 3 ), than to calculate first the angles and then the coordinates of point $C$ (with Eq. 1).

\section{Results and Discussion}

In other words, for the inverse kinematics of the module (at which the constant lengths of the two elements, 2 and 3 , i.e., $l_{2}$ and $l_{3}$, but also the positions, speeds and accelerations of the inputs, torques and/or external points, $B$ and $D$ are known $\left.x_{B}, y_{B}, \dot{x}_{B}, \dot{y}_{B}, \ddot{x}_{B}, \ddot{y}_{B}, x_{D}, y_{D}, \dot{x}_{D}, \dot{y}_{D}, \ddot{x}_{D}, \ddot{y}_{D}\right):$ Are required to determine the position angles of the two elements, 2 and 3 and their derivatives: $\varphi_{2}, \varphi_{3}, \omega_{2}, \omega_{3}, \varepsilon_{2}, \varepsilon_{3}$.

The values of the angles FI2 and FI3' depending on the input value of the angle of the crank 1, FI1, all given in degrees [deg], can be traced in the diagram in Fig. 10.

The angular velocity hodograph $w_{3}$ as a function of $w_{2}$ can be traced in Fig. 11.

The angular velocities $w_{2}$ and $w_{3}$ vary depending on the entry angle of the crank, FI1, according to the graphs in Fig. 12.

Similarly, the graph of the variation of the angular accelerations of elements 2 and 3 is obtained depending on the position of the angle FI1 (Fig. 13).

In the points of intersection of the two graphs, practically there are equal the angular velocities in Fig. 12 and the angular accelerations for the situation in Fig. 13. If 
at speeds there are two points where the angular velocities of the two different elements are equal, at accelerations, there are three such situations in which the angular accelerations of the two different elements become equal.

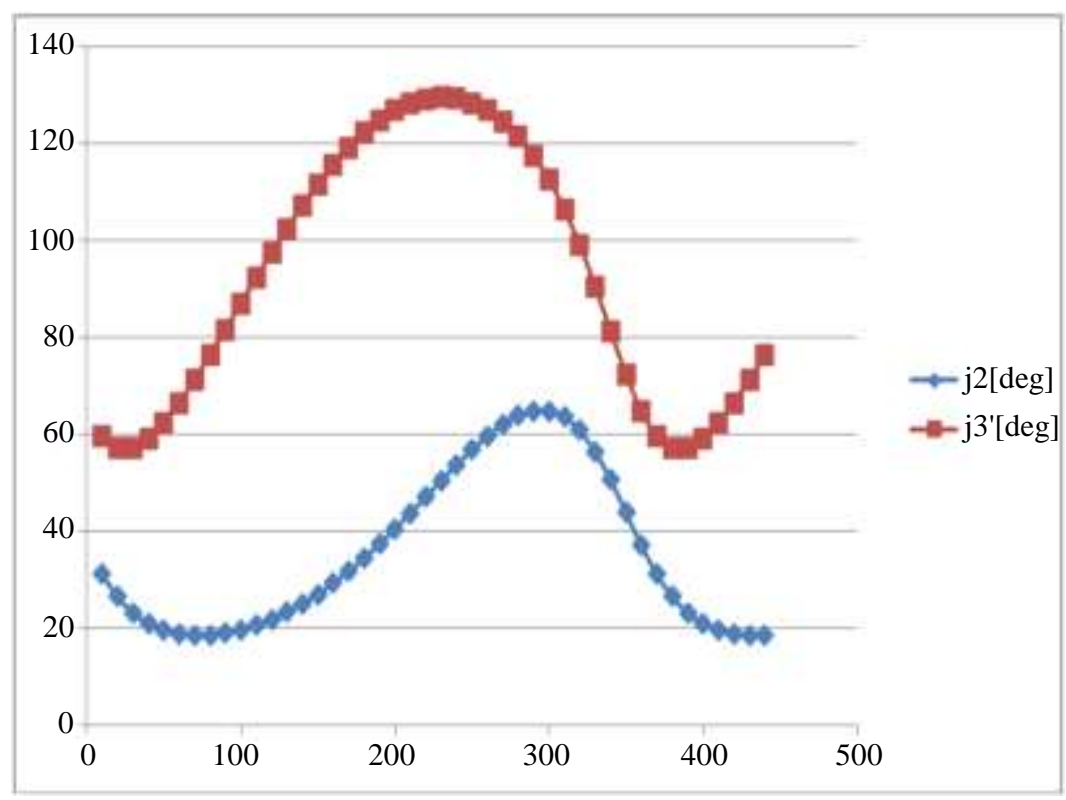

Fig. 10: The values of the angles FI2 and FI3' depending on the input value of the angle of the crank 1, FI1

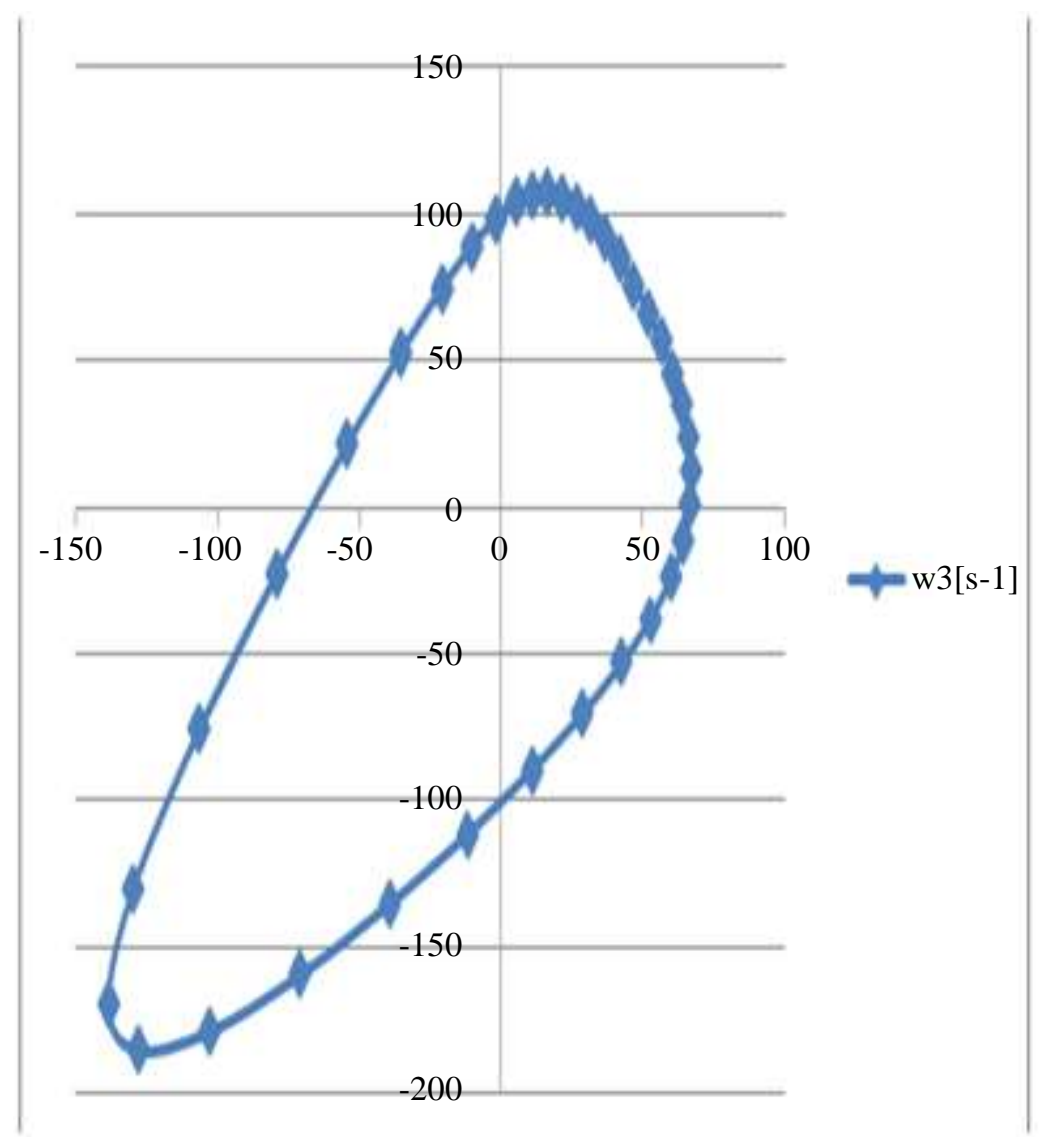

Fig. 11: The angular velocity hodograph $w_{3}$ as a function of $w_{2}$ 


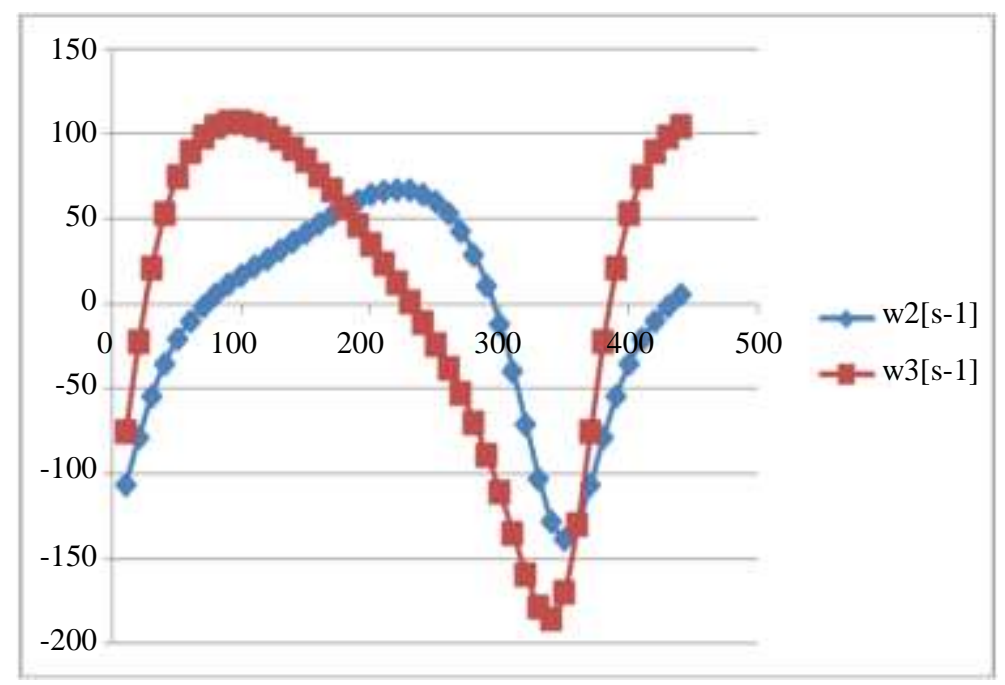

Fig. 12: The angular velocities $w_{2}$ and $w_{3}$ vary depending on the entry angle of the crank, FI1

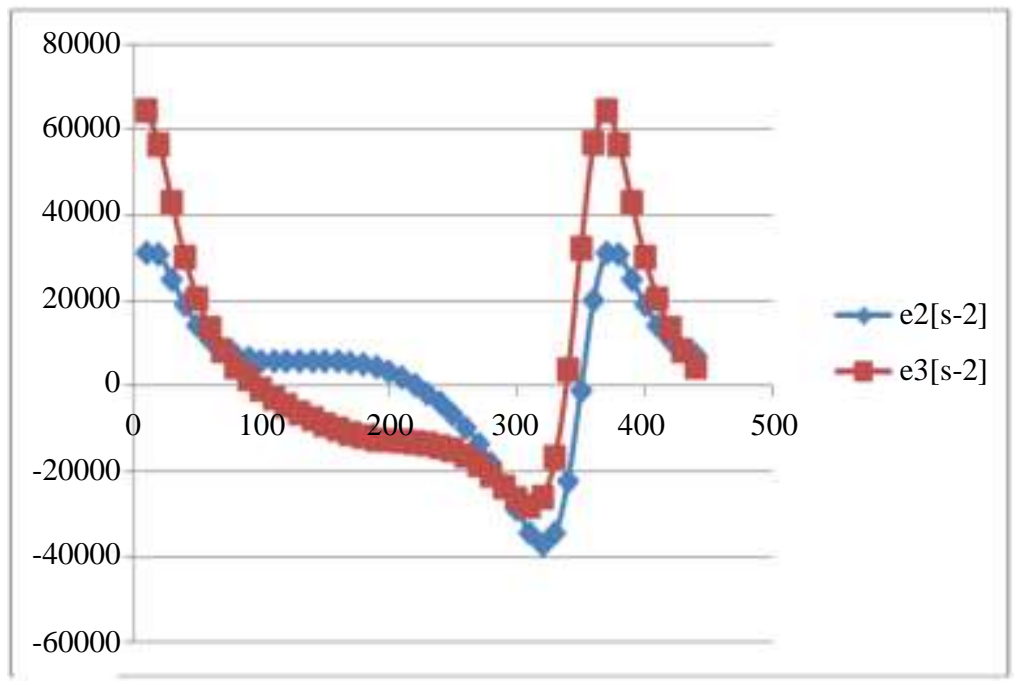

Fig. 13: The graph of the variation of the angular accelerations of elements 2 and 3 is obtained depending on the position of the angle FI1

The new method for determining positions in inverse kinematics, based on analytical geometry, will be briefly set out in the Annex.

\section{Conclusion}

The paper briefly presents the results obtained in the inverse kinematics of an anthropomorphic mechatronic basic plane module, when its exit point, end-effector describes a complete circle (whose given coordinates, known, were imposed in the work with a crank, which can be imaginary).

The graphs of the positions, velocities and angular accelerations of the elements noted with 2 and 3 of the composition of the basic plane mechatronic structure are presented.
The calculations were performed consecutively by two different methods, an older trigonometric one and a new geometro-analytical one, in both situations the results obtained being identical.

\section{Acknowledgement}

This text was acknowledged and appreciated by Dr. Veturia CHIROIU Honorific member of Technical Sciences Academy of Romania (ASTR) Ph.D. supervisor in Mechanical Engineering.

\section{Funding Information}

Research contract: Contract number 36-5-4D/1986 from 24IV1985, beneficiary CNST RO (Romanian 
National Center for Science and Technology) Improving dynamic mechanisms internal combustion engines.

!All these matters are copyrighted!

Copyrights:

- New Aircraft (New Ionic or Beam Engines): no. 548 of 22-04-2010 [cgiywDssin], Aerospace Engineering

- Some Few Specifications About the Doppler Effect to the Electromagnetic Waves: 636 of 28-05-2010 [iEtcaouxxA], physics

- Presenting an Atomic Model and Some Possible Applications in LASER Field: nr. 639 of 29-052010 [yncngrotfo], physics

- $\quad$ Some Applications in LASER Field: no. 718 of 0907-2010 [xeujouincC], physics

- The Energies of Today and Tomorrow: nr. 819 of 30-09-2010 [kbHquxwykr], energy engineering

- Obtaining Energy by the Annihilation of the Matter with Antimatter - The Battle for Energy: nr. 1068 of 13.03.2011 [GfEqpGDzeh], Energy Engineering

\section{Ethics}

This article is original and contains unpublished material. Author declares that are not ethical issues and no conflict of interest that may arise after the publication of this manuscript.

\section{References}

Anderson, S. B. (1997). Historical Overview of V/STOL Aircraft Technology. NTRS - NASA Technical Reports Server. https://ntrs.nasa.gov/citations/20020051099

Antonescu, P., \& Petrescu, F. (1985). Analytical method of synthesis of cam mechanism and flat stick. In Proceedings of the 4th International Symposium on Theory and Practice of Mechanisms, (TPM'89), Bucharest.

Antonescu, P., \& Petrescu, F. (1989). Contributions to cinetoelastodynamic analysis of distribution mechanisms.

Antonescu, P., Oprean, M., \& Petrescu, F. (1985a). Contributions to the synthesis of oscillating cam mechanism and oscillating flat stick. In Proceedings of the 4th International Symposium on Theory and Practice of Mechanisms, (TPM'85), Bucharest.

Antonescu, P., Oprean, M., \& Petrescu, F. (1985b). At the projection of the oscillate cams, there are mechanisms and distribution variables. In Proceedings of the V-Conference for Engines, Automobiles, Tractors and Agricultural Machines, I-Engines and Automobiles, (AMA'85), Brasov.
Antonescu, P., Oprean, M., \& Petrescu, F. (1986). Projection of the profile of the rotating camshaft acting on the oscillating plate with disengagement. In Proceedings of the 3rd National Computer-aided Design Symposium in the field of Mechanisms and Machine Parts, (MMP'86), Brasov.

Antonescu, P., Oprean, M., \& Petrescu, F. (1987). Dynamic analysis of the cam distribution mechanisms. In Proceedings of the 7th National Symposium on Industrial Robots and Space Mechanisms, (RSM'87), Bucharest.

Antonescu, P., Oprean, M., \& Petrescu, F. (1988). Analytical synthesis of Kurz profile, rotating the flat cam. Mach, Build. Rev.

Antonescu, P., Petrescu, F., \& Antonescu, O. (1994). Contributions to the synthesis of the rotating cam mechanism and the tip of the balancing tip.

Antonescu, P., Petrescu, F., \& Antonescu, D. (1997). Geometrical synthesis of the rotary cam and balance tappet mechanism. Bucharest, 3, 23-23.

Antonescu, P., Petrescu, F., \& Antonescu, O. (2000a). Contributions to the synthesis of the rotary disc-cam profile. In Proceedings of the 8th International Conference on the Theory of Machines and Mechanisms, (TMM'00), Liberec, Czech Republic (pp. 51-56).

Antonescu, P., Petrescu, F., \& Antonescu, O. (2000b). Synthesis of the rotary cam profile with balance follower. In Proceedings of the 8th Symposium on Mechanisms and Mechanical Transmissions, (MMT'00), Timişoara (pp. 39-44).

Antonescu, P., Petrescu, F., \& Antonescu, O. (2001). Contributions to the synthesis of mechanisms with rotary disc-cam. In Proceedings of the 8th IFToMM International Symposium on Theory of Machines and Mechanisms, (TMM'01), Bucharest, ROMANIA (pp. 31-36).

Aversa, R., Petrescu, R. V., Apicella, A., \& Petrescu, F. I. (2017a). Nano-diamond hybrid materials for structural biomedical application. American Journal of Biochemistry and Biotechnology, 13(1), 34-41.

Aversa, R., Petrescu, R. V., Akash, B., Bucinell, R., Corchado, J., Chen, G., ... \& Petrescu, F. I. (2017b). Kinematics and forces to a new model forging manipulator. American Journal of Applied Sciences, 14(1), 60-80.

Aversa, R., Petrescu, R. V., Apicella, A., Petrescu, F. I., Calautit, J. K., Bucinell, R., \& Akash, B. (2017c). Something about the $\mathrm{V}$ engines design. American Journal of Applied Sciences, 14(1), 34-52.

Aversa, R., Parcesepe, D., Petrescu, R. V., Berto, F., Chen, G., Petrescu, F. I., ... \& Apicella, A. (2017d). Processability of bulk metallic glasses. American Journal of Applied Sciences, 14(2), 294-301. 
Aversa, R., Petrescu, F. I., Petrescu, R. V., \& Apicella, A. (2016a). Biomimetic finite element analysis bone modeling for customized hybrid biological prostheses development. American Journal of Applied Sciences, 13(11), 1060-1067.

Aversa, R., Parcesepe, D., Petrescu, R. V. V., Chen, G., Petrescu, F. I. T., Tamburrino, F., \& Apicella, A. (2016b). Glassy amorphous metal injection molded induced morphological defects.

Aversa, R., Petrescu, R. V., Petrescu, F. I., \& Apicella, A. (2016c). Smart-factory: Optimization and process control of composite centrifuged pipes. American Journal of Applied Sciences, 13(11), 1330-1341.

Aversa, R., Tamburrino, F., Petrescu, R. V., Petrescu, F. I., Artur, M., Chen, G., \& Apicella, A. (2016d). Biomechanically inspired shape memory effect machines driven by muscle like acting NiTi alloys. American Journal of Applied Sciences, 13(11), 1264-1271.

Ayiei, A. (2020). The Use of Eye Tracking in Assessing Visual Attention. Journal of Aircraft and Spacecraft Technology. 4, 117-124.

Babu, K. V., Rao, A. S., Kumar, K. N., \& Rao, M. V. (2019). Spectral and luminescence properties of manganese doped sodium lead alumino borosilicate glass system. Journal of Aircraft and Spacecraft Technology, 3(1), 248-255.

Babu, K. V., Subba Rao, A., Madhuri, V., \& Suresh, K. (2020). White light generation in Dy3+-doped sodium lead alumino borosilicate glasses for WLED applications. Journal of Aircraft and Spacecraft Technology. 4(1), 39-47.

Brewer, G. D. (1991). Hydrogen aircraft technology. $\mathrm{CRC}$ press.

Brischetto, S., \& Torre, R. (2020). Honeycomb Sandwich Specimens Made of PLA and Produced Via 3D FDM Printing Process: An Experimental Study.

Cao, W., Ding, H., Zi, B., \& Chen, Z. (2013). New structural representation and digital-analysis platform for symmetrical parallel mechanisms. International Journal of Advanced Robotic Systems, $10(5), 243$.

Chaudhary, S., \& Kumar, A. (2019). Control of twin rotor MIMO system using PID and LQR controller. Journal of Aircraft and Spacecraft Technology, 3(1), 211-220.

Chilukuri, D., Yi, S., \& Seong, Y. (2019). Computer Vision for Vulnerable Road Users using Machine Learning. Journal of Mechatronics and Robotics. 3, 33-41.

CEUP. (2018). Drone: Aviation safety reform in the EU. Council of the European Union, Policies. https://www.consilium.europa.eu/ro/policies/drones/
Dekkata, S. C., \& S. Yi, (2019). Improved Steering and Adaptive Cruise Control for Autonomous Vehicles Using Model Predictive Control. Journal of Mechatronics and Robotics. 3, 378-388.

de Lima, M. S. F., de Mota Siqueira, R. H., de Carvalho, S. M., \& Abdalla, A. J. (2019). Hardening Effects of In-Situ Aging for a Laser Welded Maraging Steel.

de Mota Siqueira, R. H., Atilio, I., de Andrade Ferreira, C. C., de Carvalho, S. M., \& de Lima, M. S. F. (2020). Fiber Laser Beam Welding Between Niobium and Titanium. Journal of Aircraft and Spacecraft Technology. 4(1), 21-25.

Dong, H., Giakoumidis, N., Figueroa, N., \& Mavridis, N. (2013). Approaching behaviour monitor and vibration indication in developing a General Moving Object Alarm System (GMOAS). International Journal of Advanced Robotic Systems, 10(7), 290.

Dwivedi, A., Kumar, D., \& Tiwari, N. (2019a). A Review on Electric Traction using WE System.

Dwivedi, A., Rajbhar, P., \& Tiwari, N. (2019b). Long Distance Power Transfer Technique: A Review.

Eissa, M. A., Darwish, R. R., \& Bassiuny, A. M. (2019). New Model-Based Fault Detection Approach using Black Box Observer.

Eremia, C. (2020). Has the era of air drone wars finally settled? Defense and Security Monitor. https://monitorulapararii.ro/epoca-razboaielordronelor-aeriene-s-a-instalat-definitiv-1-31794

Fahim, S. R., Dey, S., Rashiduzzaman, M., Sarker, S. K., Badal, F. R., \& Das, S. K. (2019). Development of an Android Recognition Open-Loop Tracking Control of Writing Robotic Arm. Journal of Mechatronics and Robotics. 3, 521-533.

Franklin, D. J. (1930). Ingenious mechanisms for designers and inventors.

García, A. G. (2020). Asymptotic Stability of UnicycleLike Robots: The Bessel's Controller.

Garfo, S., Muktadir, M. A., \& Yi, S. (2020). Defect Detection on 3D Print Products and in Concrete Structures Using Image Processing and Convolution Neural Network.

Hanrahan, J. (2014). Drone Attack Survival Guide could save your life. Vice Media Group. https://www.vice.com/ro/article/53p4xz/ghidul-desupravietuire-a-atacurilor-cu-drone-ti-ar-puteasalva-viata

El Hassouni, B., Haddi, A., \& Amrani, A. G. (2019). Critical Study of Several MPPT Techniques for Photovoltaic Systems. Journal of Mechatronics and Robotics. 3, 269-279.

He, B., Wang, Z., Li, Q., Xie, H., \& Shen, R. (2013). An analytic method for the kinematics and dynamics of a multiple-backbone continuum robot. International Journal of Advanced Robotic Systems, 10(1), 84. 
Hertel, C. (2017). 10 questions you always wanted to ask a pilot. https://www.vice.com/ro/article/ne7va8/intrebaripilot-curiozitati

Kisabo, A. B., Adebimpe, A. F., \& Samuel, S. O. (2019a). Pitch Control of a Rocket with a Novel LQG/LTR Control Algorithm.

Kisabo, A. B., Nwokolo, N., Adebimpe, A. F., \& Samuel, S. O. (2019b). Novel Approach for Characterizing Solid Rocket Motor (SRM).

Kisabo, A. B., \& Adebimpe, A. F. (2019). State-Space Modeling of a Rocket for Optimal Control System Design. In Ballistics. IntechOpen.

Kortam, M. A., Tolba, F. A., \& Abdelkader Hassen, A. M. (2018). Development of a Mechatronic Control System for a Mechanical Fuel Injection System of a Four-Cylinder Automotive Diesel Engine By using Matlab and Simulink. Journal of Mechatronics and Robotics. 2, 60-71.

Kumar, R. V. N., \& Sreenivasulu, R. (2019). Inverse Kinematics (IK) Solution of a Robotic Manipulator using PYTHON. Journal of Mechatronics and Robotics. 3, 542-551.

Komakula, S. A. (2019). Optimization of Inverse Kinematic Solution of a T4R Robotic Manipulator.

Kosambe, S. (2019a). NASA's exploration missions to the red planet. Journal of Aircraft and Spacecraft Technology. 3(1), 154-171.

Kosambe, S. (2019b). Mission Shakti aka Project XSV1: India's First Anti-Satellite Test (ASAT).

Kosambe, S. (2019c). Overview of Space Debris Mitigation Activities in ISRO.

Kosambe, S. (2019d). Chandrayaan-2: India's second lunar exploration mission. Journal of Aircraft and Spacecraft Technology, 3(1), 221-236.

Langston, L. S. (2016). Hot Plates. Mechanical Engineering, 138(03), 42-47.

Langston, L. S. (2015). Gas Turbines-Major Greenhouse Gas Inhibitors. Mechanical Engineering, 137(12), 54-55.

Lee, B. J. (2013). Geometrical derivation of differential kinematics to calibrate model parameters of flexible manipulator. International Journal of Advanced Robotic Systems, 10(2), 106.

Lin, W., Li, B., Yang, X., \& Zhang, D. (2013). Modelling and control of inverse dynamics for a 5DOF parallel kinematic polishing machine. International Journal of Advanced Robotic Systems, 10(8), 314.

Liu, H., Zhou, W., Lai, X., \& Zhu, S. (2013). An efficient inverse kinematic algorithm for a PUMA560-structured robot manipulator. International Journal of Advanced Robotic Systems, $10(5), 236$.
Matthews, M. T., \& Yi, S. (2019). Adaptive and Neural Network Based Control of Pitch of Unmanned Aerial Vehicles.

Mishra, A. (2020a). Image Processing of Friction Stir Welded 6060-T5 Aluminum Alloy Joint.

Mishra, A. (2020b). Machine Learning Approach for Defects Identification in Dissimilar Friction Stir Welded Aluminium Alloys AA 7075-AA 1100 Joints.

Mishra, A., \& Sarawagi, R. (2020). Local Binary Pattern for the Evaluation of Surface Quality of Dissimilar Friction Stir Welded Ultrafine Grained 1050 and 6061-T6 Aluminium Alloys. Journal of Mechatronics and Robotics. 4, 106-112.

Nacy, S. M., \& Nayif, A. A. (2018). Effect of Object Size and Location on Contact Forces and Grasping Stability for an Underactuated Robotic Manipulator. Journal of Mechatronics and Robotics. 2, 72-84.

Oni, M. O., \& Jha, B. K. (2019). Heat Generation/absorption effect on natural convection flow in a vertical annulus with time-periodic boundary conditions. Journal of Aircraft and Spacecraft Technology, 3(1), 183-196.

Padula, F., \& Perdereau, V. (2013). An on-line path planner for industrial manipulators. International Journal of Advanced Robotic Systems, 10(3), 156.

Perumaal, S. S., \& Jawahar, N. (2013). Automated trajectory planner of industrial robot for pick-andplace task. International Journal of Advanced Robotic Systems, 10(2), 100.

Petrescu, F., \& Petrescu, R. (1995a). Contributions to optimization of the polynomial motion laws of the stick from the internal combustion engine distribution mechanism. Bucharest, 1, 249-256.

Petrescu, F., \& Petrescu, R. (1995b). Contributions to the synthesis of internal combustion engine distribution mechanisms. Bucharest, 1, 257-264.

Petrescu, F., \& Petrescu, R. (1997a). Dynamics of cam mechanisms (exemplified on the classic distribution mechanism). Bucharest, 3, 353-358.

Petrescu, F., \& Petrescu, R. (1997b). Contributions to the synthesis of the distribution mechanisms of internal combustion engines with a Cartesian coordinate method. Bucharest, 3, 359-364.

Petrescu, F., \& Petrescu, R. (1997c). Contributions to maximizing polynomial laws for the active stroke of the distribution mechanism from internal combustion engines. Bucharest, 3, 365-370.

Petrescu, F., \& Petrescu, R. (2000a). Synthesis of distribution mechanisms by the rectangular (Cartesian) coordinate method. University of Craiova, Craiova.

Petrescu, F., \& Petrescu, R. (2000b). The design (synthesis) of cams using the polar coordinate method (triangle method). University of Craiova, Craiova. 
Petrescu, F., \& Petrescu, R. (2002a). Motion laws for cams. In Proceedings of the International Computer Assisted Design, National Symposium with Participation,(SNP'02), Braşov (pp. 321-326).

Petrescu, F., \& Petrescu, R. (2002b). Camshaft dynamics elements. In Proceedings of the International Computer Assisted Design, National Participation Symposium,(SNP'02), Braşov (pp. 327-332).

Petrescu, F., \& Petrescu, R. (2003). Some elements regarding the improvement of the engine design. In Proceedings of the National Symposium, Descriptive Geometry, Technical Graphics and Design,(GTD'03), Braşov (pp. 353-358).

Petrescu, F. I., \& Petrescu, R. V. (2005a). The cam design for a better efficiency. Available at SSRN 3076805 .

Petrescu, F. I., \& Petrescu, R. V. (2005b, September). Contributions at the Dynamic of Cams. In The Ninth IFTOMM International Symposium on Theory of Machines and Mechanisms.

Petrescu, F. I., \& Petrescu, R. V. (2005c). Determining the dynamic efficiency of cams. Available at SSRN 3076802.

Petrescu, F. I., \& Petrescu, R. V. (2005d). An original internal combustion engine. In The Ninth IFTOMM International Symposium on Theory of Machines and Mechanisms.

Petrescu, R. V., \& Petrescu, F. I. (2005e). Determining the mechanical efficiency of Otto engine's mechanism. Available at SSRN 3076804.

Petrescu, F., \& Petrescu, R. (2011a). Mechanical Systems, Serial and Parallel. Lulu. com.

Petrescu, F. I. T., \& Petrescu, R. V. (2011b). Trenuri planetare. Createspace Independent Pub, 104.

Petrescu, F. I., \& Petrescu, R. V. (2011c). Determination of the Mechanical Efficiency of the Gears. INGINERIA AUTOMOBILULUI, (19), 22-23.

Petrescu, F. I., \& Petrescu, R. V. (2012a). Kinematics of the planar quadrilateral mechanism.

Petrescu, F. I., \& Petrescu, R. V. (2012b). Mecatronicasisteme seriale si paralele.

Petrescu, F. I., \& Petrescu, R. V. (2013a). Cinematics of the 3R Dyad.

Petrescu, F. I., \& Petrescu, R. V. (2013b). Cams with high efficiency. Int. Rev. Mech. Eng, 7(4), 599-606.

Petrescu, F. I. T., \& Petrescu, R. V. (2013c). An algorithm for setting the dynamic parameters of the classic distribution mechanism. Int. Rev. Modell. Simulat, 6, 1637-1641.

Petrescu, F. I., \& Petrescu, R. V. (2013d). Dynamic synthesis of the rotary cam and translated tappet with roll. Engevista, 15(3).

Petrescu, F. I., \& Petrescu, R. V. (2013e). Forces and efficiency of cams. Int. Rev. Mech. Eng, 7(3), 507-511.
Petrescu, F. I. T., \& Petrescu, R. V. V. (2014a). High efficiency gear. Facta Universitatis, Series: Mechanical Engineering, 12(1), 51-60.

Petrescu, F. I., \& Petrescu, R. V. (2014b). Cam gears dynamics in the classic distribution. Independent Journal of Management \& Production (IJM\&P), 5(1).

Petrescu, F. I., \& Petrescu, R. V. (2014c). High efficiency gears synthesis by avoid the interferences. Independent Journal of Management \& Production (IJM\&P), 5(2).

Petrescu, F. I. T., \& Petrescu, R. V. (2014d). Balancing otto engines. Int. Rev. Mech. Eng, 8, 473-480.

Petrescu, F. I. T., \& Petrescu, R. V. (2014e). Machine equations to the classical distribution. Int. Rev. Mech. Eng, 8, 309-316.

Petrescu, F. I. T., \& Petrescu, R. V. (2014f). Forces of internal combustion heat engines. Int. Rev. Modell. Simulat, 7, 206-212.

Petrescu, F. I. T., \& Petrescu, R. V. (2014g). Determination of the yield of internal combustion thermal engines. Int. Rev. Mech. Eng, 8, 62-67.

Petrescu, F. I., \& Petrescu, R. V. (2014h). Cam Dynamic Synthesis. Al-Khwarizmi Engineering Journal, 10(1), 1-23.

Petrescu, F. I., \& Petrescu, R. V. (2016a). Parallel moving mechanical systems kinematics.

Petrescu, F. I., \& Petrescu, R. V. (2016b). Direct and inverse kinematics to the anthropomorphic robots.

Petrescu, F. I., \& Petrescu, R. V. (2016c). Dynamic cinematic to a structure 2R. GEINTEC Journal, 6(2).

Petrescu, F. I. T., \& Petrescu, R. V. V. (2019a). An algorithm to determining the gear efficiency to a simple planetary train. Independent Journal of Management \& Production, 10(5), 1392-1404.

Petrescu, R. V., \& Petrescu, F. I. (2019b). StructuralTopological Synthesis of Space Mechanisms With Rods and Wheels. Independent Journal of Management \& Production (IJM\&P) v, 10.

Petrescu, F. I. T., \& Petrescu, R. V. V. (2019c). Application to rigid memory mechanisms of a variable internal dynamic damping model. Independent Journal of Management \& Production, 10(6), 1994-2022.

Petrescu, N., \& Petrescu, F. I. (2019d). The Yield of the Thermal Engines. Journal of Mechatronics and Robotics, 3, 215-236.

Petrescu, N., \& Petrescu, F. I. (2019e). Machine Motion Equations Presented in a New General Format. Journal of Mechatronics and Robotics, 3, 344-377.

Petrescu, N., \& Petrescu, F. I. (2019f). New About the Balancing of Thermal Motors. Available at SSRN 3445153.

Petrescu, R. V. V., \& Petrescu, F. I. T. (2020). About gateway. Journal of Aircraft and Spacecraft Technology. 4(1), 70-87. 
Petrescu, F.I.T., 2011. Teoria Mecanismelor si a Masinilor: Curs Si Aplicatii. 1st Edn., CreateSpace Independent Publishing Platform. ISBN-10: 1468015826. pp: 432.

Petrescu, F. I. T. (2012). Cold nuclear fusion. Plasma Phys. Fusion Technol. 44, 100-100.

Petrescu, R. V. V. (2019a). Giant success for NASA when the InSight probe has reached "safety" on Mars. Journal of Aircraft and Spacecraft Technology. 3(1), 1-10.

Petrescu, R. V. V. (2019b). Mars Could have Enough Molecular Oxygen to Support Life. Journal of Aircraft and Spacecraft Technology, 3(1), 11-23.

Petrescu, R. V. V. (2019c). About Boeing X-32. Journal of Aircraft and Spacecraft Technology, 3(1), 38-54.

Petrescu, R. V. V. (2019d). China Launches Its First Passenger Aircraft. Journal of Aircraft and Spacecraft Technology, 3, 64-77.

Petrescu, R. V. V. (2019e). NASA and the Conquest of Cosmic Space by Man. Journal of Aircraft and Spacecraft Technology, 3, 78-91.

Petrescu, R. V. V. (2019f). 'Defiant', A Today Unique Helicopter in the World. Journal of Aircraft and Spacecraft Technology, 3, 92-106.

Petrescu, R. V. V. (2019g). The TESS Satellite Will Search for Planets in the Vicinity of Our Solar System. Journal of Aircraft and Spacecraft Technology, 3, 107-118.

Petrescu, R. V. V. (2019h). Boeing's Autonomous Military Aircraft. Journal of Aircraft and Spacecraft Technology, 3, 138-153.

Petrescu, F. I. T. (2019i). About the nuclear particles' structure and dimensions. Computational Particle Mechanics, 6(2), 191-194.

Petrescu, R. V. (2019j). About the Space Robots. Journal of Mechatronics and Robotics, 3, 1-32.

Petrescu, R. V. (2019k). Medical service of robots. Journal of Mechatronics and Robotics, 3, 60-81.

Petrescu, R. V. (20191). Dynamics at Classical Distribution. Journal of Mechatronics and Robotics, 3, 82-101.

Petrescu, R. V. (2019m). Time Factory. Journal of Mechatronics and Robotics, 3, 102-121.

Petrescu, R. V. (2019n). About Robotics, Mechatronics and Automation that Help us Conquer the Cosmic Space. Journal of Mechatronics and Robotics, 3, 129-155.

Petrescu, R. V. (2019o). Dynamic Models for Rigid Memory Mechanisms. Journal of Mechatronics and Robotics, 3, 156-183.

Petrescu, R. V. (2019p). Something about a Railbound Forging Manipulator. Journal of Mechatronics and Robotics, 3, 184-207.

Petrescu, R. V. (2019q). Face Recognition as a Biometric Application. Journal of Mechatronics and Robotics, 3, 237-257.
Petrescu, R. V. (2019r). Contributions to the Synthesis of Fixed Axle Gears by Avoiding the Interference Phenomenon. Journal of Mechatronics and Robotics, 3, 280-300.

Petrescu, R. V. (2019s). Space Probes. Journal of Mechatronics and Robotics, 3, 301-343.

Petrescu, R. V. (2019t). Presents Some Aspects and Applications of Projective Geometry. Available at SSRN 3445158.

Petrescu, R. V. (2019u). Mechanisms With Rigid Memory. Journal of Mechatronics and Robotics, 3, 431-470.

Petrescu, R. V. (2019v). Internal Combustion Engines Forces. Journal of Mechatronics and Robotics, 3, 497-520.

Petrescu, R. V. V. (2020a). British Airways is Ordering up to 42 Boeing 777-9s Aeronaves to Modernize the UK Flag Carriers Long-Haul Fleet.

Petrescu, R. V. V. (2020b). Presentation of Four-stroke Engine Design Elements. Journal of Mechatronics and Robotics, 4, 15-41.

Petrescu, R. V. V. (2020c). Presents the Kinematics and Forces at a Basic Anthropomorphic Robot. Journal of Mechatronics and Robotics, 4, 42-73.

Petrescu, R. V. V. (2020d). Presents the Kinematics of a Manipulator with Three Mobilities. Journal of Mechatronics and Robotics, 4, 85-105.

Petrescu, R. V. V. (2020e). Nanobotics. Journal of Mechatronics and Robotics, 4, 136-155.

Petrescu, R. V. V. (2020f). Mechatronic Systems to the Braking Mechanisms. Journal of Mechatronics and Robotics, 4, 156-190.

Petrescu, R. V. V. (2020g). Fishing for "16 Psyche". Journal of Aircraft and Spacecraft Technology, 4, 136-151.

Petrescu, R. V., Petrescu, F. I., \& Popescu, N. (2007). Determining gear efficiency. Gear Solutions.

Petrescu, F. I., Grecu, B., Comanescu, A., \& Petrescu, R. V. (2009, October). Some mechanical design elements. In The 3rd International Conference on Computational Mechanics and Virtual Engineering COMEC (pp. 29-30).

Petrescu, F. I., Apicella, A., Petrescu, R. V., Kozaitis, S., Bucinell, R., Aversa, R., \& Abu-Lebdeh, T. (2016). Environmental protection through nuclear energy. American Journal of Applied Sciences, 13(9), 941-946.

Petrescu, R. V., Aversa, R., Akash, B., Bucinell, R., Corchado, J., Apicella, A., \& Petrescu, F. I. (2017a). Modern propulsions for aerospace-a review. Journal of Aircraft and Spacecraft Technology, 1(1).

Petrescu, R. V., Aversa, R., Akash, B., Bucinell, R., Corchado, J., Apicella, A., \& Petrescu, F. I. (2017b). Modern propulsions for aerospace-part II. Journal of Aircraft and Spacecraft Technology, 1(1). 
Petrescu, R. V., Aversa, R., Akash, B., Bucinell, R., Corchado, J., Apicella, A., \& Petrescu, F. I. (2017c). History of aviation-a short review. Journal of Aircraft and Spacecraft Technology, 1(1).

Petrescu, R. V., Aversa, R., Akash, B., Bucinell, R., Corchado, J., Apicella, A., \& Petrescu, F. I. (2017d). Lockheed martin-a short review. Journal of Aircraft and Spacecraft Technology, 1(1).

Petrescu, R. V., Aversa, R., Akash, B., Corchado, J., Apicella, A., \& Petrescu, F. I. (2017e). Our universe. Journal of Aircraft and Spacecraft Technology, 1(2).

Petrescu, R. V., Aversa, R., Akash, B., Corchado, J., Apicella, A., \& Petrescu, F. I. (2017f). What is a UFO?. Journal of Aircraft and Spacecraft Technology, 1(2).

Petrescu, R. V., Aversa, R., Akash, B., Corchado, J., Berto, F., Mirsayar, M., ... \& Petrescu, F. I. T. (2017g). About bell helicopter FCX-001 concept aircraft-a short review. Journal of Aircraft and Spacecraft Technology, 1(2), 91-96.

Petrescu, R. V., Aversa, R., Akash, B., Corchado, J., Apicella, A., \& Petrescu, F. I. (2017h). Home at airbus. Journal of Aircraft and Spacecraft Technology, 1(2).

Petrescu, R. V., Aversa, R., Akash, B., Corchado, J., Kozaitis, S., Abu-Lebdeh, T., ... \& Petrescu, F. I. (2017i). Airlander. Journal of Aircraft and Spacecraft Technology, 1(2).

Petrescu, R. V., Aversa, R., Akash, B., Corchado, J., Berto, F., Apicella, A., \& Petrescu, F. I. (2017j). When boeing is dreaming-a review. Journal of Aircraft and Spacecraft Technology, 1(3).

Petrescu, R. V., Aversa, R., Akash, B., Corchado, J., Berto, F., Apicella, A., \& Petrescu, F. I. (2017k). About northrop grumman. Journal of Aircraft and Spacecraft Technology, 1(3).

Petrescu, R. V., Aversa, R., Akash, B., Corchado, J., Berto, F., Apicella, A., \& Petrescu, F. I. (20171). Some special aircraft. Journal of Aircraft and Spacecraft Technology, 1(3).

Petrescu, R. V., Aversa, R., Akash, B., Corchado, J., Berto, F., Apicella, A., \& Petrescu, F. I. (2017m). About helicopters. Journal of Aircraft and Spacecraft Technology, 1(3), 204-223.

Petrescu, R. V., Aversa, R., Akash, B., Berto, F., Apicella, A., \& Petrescu, F. I. (2017n). The modern flight. Journal of Aircraft and Spacecraft Technology, 1(4), 224-233.

Petrescu, R. V., Aversa, R., Akash, B., Berto, F., Apicella, A., \& Petrescu, F. I. (2017o). Sustainable energy for aerospace vessels. Journal of Aircraft and Spacecraft Technology, 1(4), 234-240.

Petrescu, R. V., Aversa, R., Akash, B., Berto, F., Apicella, A., \& Petrescu, F. I. (2017p). Unmanned helicopters. Journal of Aircraft and Spacecraft Technology, 1(4), 241-248.
Petrescu, R. V., Aversa, R., Akash, B., Berto, F. Apicella, A., \& Petrescu, F. I. (2017q). Project HARP. Journal of Aircraft and Spacecraft Technology, 1(4), 249-257.

Petrescu, R. V., Aversa, R., Akash, B., Berto, F., Apicella, A., \& Petrescu, F. I. (2017r). Presentation of Romanian Engineers who Contributed to the Development of Global Aeronautics-Part I. Journal of Aircraft and Spacecraft Technology, 1(4), 258-271.

Petrescu, R. V., Aversa, R., Akash, B., Berto, F., Apicella, A., \& Petrescu, F. I. (2017s). A first-class ticket to the planet mars, please. Journal of Aircraft and Spacecraft Technology, 1(4), 272-281.

Petrescu, R. V., Aversa, R., Li, S., Bucinell, R., Kozaitis, S., Abu-Lebdeh, T., ... \& Petrescu, F. I. (2017t). Electron dimensions. American Journal of Engineering and Applied Sciences, 10(2), 584-602.

Petrescu, R. V., Aversa, R., Kozaitis, S., Apicella, A., \& Petrescu, F. I. (2017u). Deuteron dimensions. American Journal of Engineering and Applied Sciences, 10(3).

Petrescu, R. V., Aversa, R., Kozaitis, S., Apicella, A., \& Petrescu, F. I. (2017v). Some proposed solutions to achieve nuclear fusion. American Journal of Engineering and Applied Sciences, 10(3).

Petrescu, R. V., Aversa, R., Kozaitis, S., Apicella, A., \& Petrescu, F. I. (2017w). Some basic reactions in nuclear fusion. American Journal of Engineering and Applied Sciences, 10(3).

Petrescu, F. I. T., Petrescu, R. V., \& Mirsayar, M. (2017x). The computer algorithm for machine equations of classical distribution. Journal of Materials and Engineering Structures «JMES», 4(4), 193-209.

Petrescu, R. V., Aversa, R., Apicella, A., Kozaitis, S., Abu-Lebdeh, T., Akash, B., \& Petrescu, F. I. (2017y). Triton for nuclear fusion. American Journal of Engineering and Applied Sciences, 10(4).

Petrescu, R. V., Aversa, R., Akash, B., Berto, F., Apicella, A., \& Petrescu, F. I. (2017z). Forces of a 3R robot. Journal of Mechatronics and Robotics, 1(1).

Petrescu, R. V., Aversa, R., Akash, B., Berto, F., Apicella, A., \& Petrescu, F. I. (2017aa). Direct geometry and cinematic to the MP-3R systems. Journal of Mechatronics and Robotics, 1(1).

Petrescu, R. V., Aversa, R., Akash, B., Berto, F., Apicella, A., \& Petrescu, F. I. (2017ab). Dynamic elements at MP3R. Journal of Mechatronics and Robotics, 1(2), 24-37.

Petrescu, R. V., Aversa, R., Akash, B., Berto, F., Apicella, A., \& Petrescu, F. I. (2017ac). Geometry and direct kinematics to MP3R with $4 \times 4$ operators. Journal of Mechatronics and Robotics, 1(2), 38-46. 
Petrescu, R. V., Aversa, R., Apicella, A., Kozaitis, S., AbuLebdeh, T., \& Petrescu, F. I. (2017ad). Current stage in the field of mechanisms with gears and rods. Journal of Mechatronics and Robotics, 1(2), 47-57.

Petrescu, R. V., Aversa, R., Apicella, A., Kozaitis, S., Abu-Lebdeh, T., \& Petrescu, F. I. (2017ae). Geometry and inverse kinematic at the MP3R mobile systems. Journal of Mechatronics and Robotics, 1(2), 58-65.

Petrescu, R. V., Aversa, R., Apicella, A., Kozaitis, S., Abu-Lebdeh, T., \& Petrescu, F. I. (2017af). Synthesis of optimal trajectories with functions control at the level of the kinematic drive couplings. Journal of Mechatronics and Robotics, 1(2), 66-74.

Petrescu, R. V., Aversa, R., Apicella, A., Kozaitis, S., Abu-Lebdeh, T., \& Petrescu, F. I. (2017ag). The inverse kinematics of the plane system 2-3 in a mechatronic MP2R system, by a trigonometric method. Journal of Mechatronics and Robotics, 1(2), 75-87.

Petrescu, R. V., Aversa, R., Apicella, A., Kozaitis, S., Abu-Lebdeh, T., \& Petrescu, F. I. (2017ah). Serial, anthropomorphic, spatial, mechatronic systems can be studied more simply in a plan. Journal of Mechatronics and Robotics, 1(2), 88-97.

Petrescu, R. V., Aversa, R., Apicella, A., Kozaitis, S., Abu-Lebdeh, T., \& Petrescu, F. I. (2017ai). Analysis and synthesis of mechanisms with bars and gears used in robots and manipulators. Journal of Mechatronics and Robotics, 1(2), 98-108.

Petrescu, R. V., Aversa, R., Apicella, A., Kozaitis, S., Abu-Lebdeh, T., \& Petrescu, F. I. (2017aj). Speeds and accelerations in direct kinematics to the MP3R systems. Journal of Mechatronics and Robotics, 1(2), 109-117.

Petrescu, R. V., Aversa, R., Apicella, A., Kozaitis, S., Abu-Lebdeh, T., \& Petrescu, F. I. (2017ak). Geometry and determining the positions of a plan transporter manipulator. Journal of Mechatronics and Robotics, 1(2), 118-126.

Petrescu, R. V., Aversa, R., Apicella, A., \& Petrescu, F. I. (2018a). Romanian Engineering'On the Wings of the Wind'. Journal of Aircraft and Spacecraft Technology, 2(1), 1-18.

Petrescu, R. V., Aversa, R., Apicella, A., \& Petrescu, F. I. (2018b). NASA Data used to discover eighth planet circling distant star. Journal of Aircraft and Spacecraft Technology, 2(1), 19-30.

Petrescu, R. V., Aversa, R., Apicella, A., \& Petrescu, F. I. (2018c). NASA has found the most distant black hole. Journal of Aircraft and Spacecraft Technology, 2(1), 31-39.

Petrescu, R. V., Aversa, R., Apicella, A., \& Petrescu, F. I. (2018d). Nasa selects concepts for a new mission to titan, the moon of saturn. Journal of Aircraft and Spacecraft Technology, 2(1), 40-52.
Petrescu, R. V., Aversa, R., Apicella, A., \& Petrescu, F. I. (2018e). NASA sees first in 2018 the direct proof of ozone hole recovery. Journal of Aircraft and Spacecraft Technology, 2(1), 53-64.

Petrescu, R. V., Aversa, R., Apicella, A., \& Petrescu, F. I. (2018f). An Exoplanet has Smothering Stratosphere without Water. Relly Victoria Petrescu et al./Journal of Aircraft and Spacecraft Technology, 2, 65-71.

Petrescu, R. V., Aversa, R., Apicella, A., \& Petrescu, F. I. (2018g). Structure of Buried Ice on Mars. Relly Victoria Petrescu et al./Journal of Aircraft and Spacecraft Technology, 2, 72-79.

Petrescu, N., Aversa, R., Apicella, A., \& Petrescu, F. I. (2018h). A New Exoplanet Reveals its Identity. Nicolae Petrescu et al./Journal of Aircraft and Spacecraft Technology, 2, 85-96.

Petrescu, N., Aversa, R., Apicella, A., \& Petrescu, F. I. (2018i). New Researches Examines the Wing Shapes to Reduce Vortex and Wake. Journal of Aircraft and Spacecraft Technology, 2, 97-110.

Petrescu, R. V., Aversa, R., Apicella, A., \& Petrescu, F. I. (2018j). Romanian Engineering'On the Wings of the Wind'. Journal of Aircraft and Spacecraft Technology, 2(1), 1-18.

Petrescu, R. V., Aversa, R., Apicella, A., \& Petrescu, F. I. (2018k). NASA Data used to discover eighth planet circling distant star. Journal of Aircraft and Spacecraft Technology, 2(1), 19-30.

Petrescu, R. V., Aversa, R., Apicella, A., \& Petrescu, F. I. (20181). NASA has found the most distant black hole. Journal of Aircraft and Spacecraft Technology, 2(1), 31-39.

Petrescu, R. V., Aversa, R., Apicella, A., \& Petrescu, F. I. (2018m). Nasa selects concepts for a new mission to titan, the moon of saturn. Journal of Aircraft and Spacecraft Technology, 2(1), 40-52.

Petrescu, R. V., Aversa, R., Apicella, A., \& Petrescu, F. I. (2018n). NASA sees first in 2018 the direct proof of ozone hole recovery. Journal of Aircraft and Spacecraft Technology, 2(1), 53-64.

Petrescu, R. V., Aversa, R., Apicella, A., \& Petrescu, F. I. (20180). Modern propulsions for the aerospace industry. American Journal of Engineering and Applied Sciences, 11(2), 715-755.

Petrescu, R. V., Aversa, R., Apicella, A., Kozaitis, S., Abu-Lebdeh, T., \& Petrescu, F. I. (2018p). Inverse kinematics of a stewart platform. Journal of Mechatronics and Robotics, 2(1), 45-59.

Petrescu, R. V., Aversa, R., Apicella, A., \& Petrescu, F. I. (2018q). Total static balancing and kinetostatics of the $3 \mathrm{R}$ base cinematic Chain. Journal of Mechatronics and Robotics, 2(1), 1-13.

Petrescu, R. V., Aversa, R., Apicella, A., \& Petrescu, F. I. (2018r). Switching from flat to spatial motion to 3R mechatronic systems. Journal of Mechatronics and Robotics, 2(1), 14-22. 
Petrescu, R. V., Aversa, R., Apicella, A., \& Petrescu, F. I. (2018s). The dynamics of the planar cinematic balanced chain at the plan module $3 R$. Journal of Mechatronics and Robotics, 2(1), 23-34.

Petrescu, R. V., Aversa, R., Apicella, A., \& Petrescu, F. I. (2018t). Dynamic kinematics of the plan balanced chain at the planar module 3R. Journal of Mechatronics and Robotics, 2(1), 35-44.

Petrescu, R. V., Aversa, R., Apicella, A., Kozaitis, S., Abu-Lebdeh, T., \& Petrescu, F. I. (2018u). Inverse kinematics of a stewart platform. Journal of Mechatronics and Robotics, 2(1), 45-59.

Petrescu, N., Aversa, R., Apicella, A., \& Petrescu, F. I. (2018v). Something about Robots Today. Journal of Mechatronics and Robotics, 2, 85-104.

Petrescu, N., Aversa, R., Apicella, A., \& Petrescu, F. I. (2018w). Structural-Topological Synthesis of Planar Mechanisms with Rods and Wheels. Journal of Mechatronics and Robotics, 2, 105-120.

Petrescu, R. V. V., Aversa, R., \& Apicella, A. (2020). Structural colour from optical phenomena caused by interference with a thin or multilayer film, photonic nanocrystals, light scattering and diffraction grating effect. Journal of Aircraft and Spacecraft Technology. 4(1), 117-143.

Petrescu, F. I., \& Calautit, J. K. (2016a). About nano fusion and dynamic fusion. American Journal of Applied Sciences, 13(3).

Petrescu, F. I., \& Calautit, J. K. (2016b). About the light dimensions. American Journal of Applied Sciences, 13(3).

Rahman, Z. A. (2018). On a New Equation for the Design and Development of Space Launch Vehicles. Journal of Aircraft and Spacecraft Technology, 2(1), 80-84.

Rana, S. (2020). Improved 3D Imaging Performance of AFM. Journal of Mechatronics and Robotics, 4, 8-14.

Richmond, B. (2013). Kristian von Bengtson, Space Mission.

https://www.vice.com/ro/article/4xdb5g/primamisiune-cu-pilot-pe-luna-lui-jupiter-va-fiplanificata-prin-crowdsourcing

Riman, C. F. (2018). Multi-Controlled Wheelchair for Upper Extremities Disability. Journal of Mechatronics and Robotics, 2, 121-131.

Riman, C. F. (2019). Cheap Bluetooth Solution for Smart Controlled Home Devices. Journal of Mechatronics and Robotics, 3, 589-595.

Saheed, A., Adeyinka, O. M., \& Zulikha, A. B. (2019). Access Control, Fire Prevention and Surveillance Security System. Journal of Mechatronics and Robotics, 3, 563-570.
Sharma, A., \& Kosambe, S. (2020). Trajectory optimization for first human asteroid exploration mission. Journal of Aircraft and Spacecraft Technology. 4(1), 96-116.

Svensson, F., Hasselrot, A., \& Moldanova, J. (2004). Reduced environmental impact by lowered cruise altitude for liquid hydrogen-fuelled aircraft. Aerospace Science and Technology, 8(4), 307-320.

Tumino, D. (2020). Mathematical formulation and numerical implementation of a finite element with anisotropic geometry. Journal of Aircraft and Spacecraft Technology. 4(1), 26-38.

Vladescu, I. (2020). The flying car exists. The US Air Force has successfully tested it. https://evz.ro/gatamasina-zburatoare-exista-us-air-force-a-testat-o-cusucces.html?utm_source=onesignal\&fbclid=IwAR3 WWmFTIz_DBQAAwpWIDC3zsLJFaZ5KiKJsGx7 vaiuCkx_2JTuOWn2YuSQ

Welabo, A., \& Tesfamariamr, G. (2020). Trajectory Tracking Control of UR5 Robot Manipulator Using Fuzzy Gain Scheduling Terminal Sliding Mode Controller. Journal of Mechatronics and Robotics, 4, 113-135.

Welch, H., \& Mondal, S. (2019). Analysis of Magnetic Wheel Adhesion Force for Climbing Robot. Journal of Robotics and Mechatronics, 3, 534-541.

Younes, T. M., AlKhedher, M. A., SOLIMAN, A. H., \& Al Alawin, A. (2019). Design and Implementation of Myoelectric Controlled Arm. Journal of Mechatronics and Robotics, 3(1), 552-562.

\section{Source of Figures}

Fig. 1: https://www.auto-bild.ro/stiri/de-ceinlocuieste-mercedes-roboti-cu-oameni-92233.html

Fig.

2:

http://www.automaticbagpackingmachine.com/sale9566254-industrial-fully-automated-welding-productionline-plc-control-for-car-industry.html

Fig. 3: https://www.swipeguide.com/insights/humanworkers-industry-tesla

Fig. 4: https://www.dreamstime.com/welding-carbody-automotive-production-line-long-format-wideframe-assembly-line-production-new-car-automatedwelding-car-image 133841638

Fig.

5: https://www.youtube.com/watch?v=9fjnMJauGwU

Fig. 6-13: Made by author

\section{Appendix}

The new, geometric-analytical equations used are the following (system 4): 


$$
\left\{\begin{array}{l}
y_{C}=\left[\left(b^{2}+c^{2}-a^{2}\right) \cdot h+p \cdot d .\right. \\
\left.\sqrt{2\left(a^{2} b^{2}+a^{2} c^{2}+b^{2} c^{2}\right)-\left(a^{4}+b^{4}+c\right)}\right] /\left(2 c^{2}\right) \\
+y_{D} \\
x_{C}=\frac{b^{2}+c^{2}-a^{2}-2 h \cdot y_{C}}{2 d}+x_{D} \\
h=y_{B}-y_{D} \\
d=x_{B}-x_{D}
\end{array}\right.
$$

where a is the length of element $2, b$ represents the length of element $3, c$ is the variable length of the segment joining the two input couplings in the plane mechatronic module, the input torques of the mechatronic module being denoted by $B$ and $D$ and its inner torque being denoted with $C$; the Cartesian coordinates of the input torques $B$ and $D$ are known, while the coordinates of the inner point $C$ must be determined. With $\mathrm{h}$ the difference in height between the entry points in mode $B$ and $D$ was noted, while with $d$ the horizontal difference between the same input couplings $B$ and $D$ was noted, according to the last two relations in the system below. The $p$ parameter is a negative or positive sign, a counter that can take the value -1 or 1 .

The equations of the older trigonometric method are mentioned in the system (5):

$$
\begin{aligned}
& \left\{\begin{array}{l}
l_{1}=0.1[\mathrm{~m}] ; \quad l_{2}=0.3[\mathrm{~m}] ; \quad l_{3}=0.2[\mathrm{~m}] ; \quad x_{D} \equiv l_{0}=0.254[\mathrm{~m}] ; \quad y_{D}=0 ; \\
\left\{\begin{array}{l}
x_{B}=l_{1} \cdot \cos \varphi_{1} \\
y_{B}=l_{1} \cdot \sin \varphi_{1}
\end{array}\right. \\
\left\{\begin{array}{l}
\dot{x}_{B}=-l_{1} \cdot \sin \varphi_{1} \cdot \omega_{1} \\
\dot{y}_{B}=l_{1} \cdot \cos \varphi_{1} \cdot \omega_{1}
\end{array} ;\left\{\begin{array}{l}
\ddot{x}_{B}=-l_{1} \cdot \cos \varphi_{1} \cdot \omega_{1}^{2} \\
\ddot{y}_{B}=-l_{1} \cdot \sin \varphi_{1} \cdot \omega_{1}^{2}
\end{array} ;\left\{\begin{array}{l}
\dot{x}_{D}=0 \\
\dot{y}_{D}=0
\end{array} ;\left\{\begin{array}{l}
\ddot{x}_{D}=0 \\
\ddot{y}_{D}=0
\end{array} ;\left\{\begin{array}{l}
l^{2}=\left(x_{D}-x_{B}\right)^{2}+\left(y_{D}-y_{B}\right)^{2} \\
l=\sqrt{\left(x_{D}-x_{B}\right)^{2}+\left(y_{D}-y_{B}\right)^{2}}
\end{array}\right.\right.\right.\right.\right.
\end{array}\right. \\
& \sin \varphi=\frac{y_{D}-y_{B}}{l} ; \cos \varphi=\frac{x_{D}-x_{B}}{l} ; \varphi=\operatorname{semn}(\sin \varphi) \cdot \arccos (\cos \varphi) \Rightarrow \\
& \Rightarrow \varphi=\operatorname{semn}\left(\frac{y_{D}-y_{B}}{l}\right) \cdot \arccos \left(\frac{x_{D}-x_{B}}{l}\right) \\
& \left\{\begin{array} { l } 
{ \operatorname { c o s } B = \frac { l ^ { 2 } + l _ { 2 } ^ { 2 } - l _ { 3 } ^ { 2 } } { 2 \cdot l \cdot l _ { 2 } } \Rightarrow B = \operatorname { a r c c o s } ( \operatorname { c o s } B ) = \operatorname { a r c c o s } ( \frac { l ^ { 2 } + l _ { 2 } ^ { 2 } - l _ { 3 } ^ { 2 } } { 2 \cdot l \cdot l _ { 2 } } ) } \\
{ \operatorname { c o s } D = \frac { l ^ { 2 } + l _ { 3 } ^ { 2 } - l _ { 2 } ^ { 2 } } { 2 \cdot l \cdot l _ { 3 } } \Rightarrow D = \operatorname { a r c c o s } ( \operatorname { c o s } D ) = \operatorname { a r c c o s } ( \frac { l ^ { 2 } + l _ { 3 } ^ { 2 } - l _ { 2 } ^ { 2 } } { 2 \cdot l \cdot l _ { 3 } } ) }
\end{array} \Rightarrow \left\{\begin{array}{l}
\varphi_{2}=\varphi \pm \hat{B} \Rightarrow \varphi_{2}=\varphi+\hat{B} \\
\varphi_{3}=\varphi \mp \hat{D} \Rightarrow \varphi_{3}=\varphi-\hat{D}
\end{array}\right.\right. \\
& \omega_{2}=\frac{\left(\dot{x}_{D}-\dot{x}_{B}\right) \cdot \cos \varphi_{3}+\left(\dot{y}_{D}-\dot{y}_{B}\right) \cdot \sin \varphi_{3}}{l_{2} \cdot \sin \left(\varphi_{3}-\varphi_{2}\right)}=\frac{l_{1}}{l_{2}} \cdot \frac{\sin \left(\varphi_{1}-\varphi_{3}\right)}{\sin \left(\varphi_{3}-\varphi_{2}\right)} \cdot \omega_{1} \\
& \omega_{3}=\frac{\left(\dot{x}_{D}-\dot{x}_{B}\right) \cdot \cos \varphi_{2}+\left(\dot{y}_{D}-\dot{y}_{B}\right) \cdot \sin \varphi_{2}}{l_{3} \cdot \sin \left(\varphi_{2}-\varphi_{3}\right)}=\frac{l_{1}}{l_{3}} \cdot \frac{\sin \left(\varphi_{1}-\varphi_{2}\right)}{\sin \left(\varphi_{2}-\varphi_{3}\right)} \cdot \omega_{1} \\
& \varepsilon_{2}=\frac{\left(\ddot{x}_{D}-\ddot{x}_{B}\right) \cdot \cos \varphi_{3}+\left(\ddot{y}_{D}-\ddot{y}_{B}\right) \cdot \sin \varphi_{3}+l_{2} \cdot \omega_{2}^{2} \cdot \cos \left(\varphi_{3}-\varphi_{2}\right)+l_{3} \cdot \omega_{3}^{2}}{l_{2} \cdot \sin \left(\varphi_{3}-\varphi_{2}\right)} \\
& \varepsilon_{3}=\frac{\left(\ddot{x}_{D}-\ddot{x}_{B}\right) \cdot \cos \varphi_{2}+\left(\ddot{y}_{D}-\ddot{y}_{B}\right) \cdot \sin \varphi_{2}+l_{2} \cdot \omega_{2}^{2}+l_{3} \cdot \omega_{3}^{2} \cdot \cos \left(\varphi_{2}-\varphi_{3}\right)}{l_{3} \cdot \sin \left(\varphi_{2}-\varphi_{3}\right)}
\end{aligned}
$$

